\title{
Higher Concentration of Taenia Antigens in the CSF is Related to Slight Ventricle Enlargement and Periventricular Neuronal Decrease in Young Rats
}

\section{Maior concentração de antígenos de Taenia está associada a ligeiro aumento de ventrículos e redução de neurônios periventriculares em ratos jovens}

\author{
Mônica Almeida Silva ${ }^{1}$ Eduardo Vieira Barcelos ${ }^{1}$ Aderaldo Costa Aves Júnior ${ }^{1(0)}$ Diego Generoso ${ }^{1(1)}$ \\ Maiara Almeida Aldá2@ Sabrina Setembre Batah ${ }^{2}$ Alexandre Todorovic Fabro ${ }^{2}$ () \\ Vânia Maria de Vasconcelos Machado ${ }^{3}$ Pedro Tadao Hamamoto Filho ${ }^{10}$ Marco Antônio Zanini ${ }^{10}$
}

\footnotetext{
${ }^{1}$ Department of Neurology, Psychology and Psychiatry, Botucatu Medical School , Universidade Estadual Paulista, Botucatu, SP, Brazil

${ }^{2}$ Department of Pathology and Legal Medicine, Ribeirão Preto Medical School, Universidade de São Paulo, Ribeirão Preto, SP, Brazil

${ }^{3}$ Department of Animal Reproduction and Veterinary Radiology,

School of Veterinary Medicine and Animal Sciences, Universidade Estadual Paulista, Botucatu, Brazil
}

Arq Bras Neurocir 2021;40(2):e146-e151.

\author{
Address for correspondence Pedro Tadao Hamamoto Filho, MD, PhD, \\ Departamento de Neurologia, Psicologia e Psiquiatria, UNESP - \\ Campus de Botucatu, Distrito de Rubião Jr, s/n, Botucatu, Brazil \\ (e-mail: pedro.hamamoto@unesp.br).
}

\begin{abstract}
Keywords

- neurocysticercosis

- hydrocephalus

- neurons

- experimental model
\end{abstract}

Purpose Experimental models might help understand the pathophysiology of neurocysticercosis-associated hydrocephalus. The present study aimed to compare the extent of hydrocephalus and tissue damage in rats with subarachnoid inoculation of different concentrations of Taenia crassiceps cyst proteins.

Methods Sixty young rats were divided into two groups: low- and high-concentration groups. The animals in the low concentration group received $0.02 \mathrm{ml}$ of $2.4 \mathrm{mg} / \mathrm{ml} \mathrm{T}$. crassiceps cyst proteins while those in the high concentration group received $0.02 \mathrm{ml}$ of $11.6 \mathrm{mg} / \mathrm{ml}$. crassiceps cyst proteins. The animals underwent magnetic resonance imaging at 1,3 , and 6 months postinoculation to assess the ventricle volume. Morphological assessment was performed at the end of the observation period.

Results Repeated measures of ventricle volumes at 1, 3, and 6 months showed progressive enlargement of the ventricles. At 1 and 3 months, we observed no differences in ventricle volumes between the 2 groups. However, at 6 months, the ventricles were larger in the high concentration group (median $=3.86 \mathrm{~mm}^{3}$, range: 2.37-12.68) compared with the low concentration group (median $=2.00 \mathrm{~mm}^{3}$, range: $0.37-11.57), p=0.003$. The morphological assessment revealed a few received

July 3, 2020

accepted

August 24, 2020

published online

November 26, 2020
DOI https://doi.org/ 10.1055/s-0040-1718997. ISSN 0103-5355.

\footnotetext{
(c) 2020. Sociedade Brasileira de Neurocirurgia. All rights reserved. This is an open access article published by Thieme under the terms of the Creative Commons Attribution-NonDerivative-NonCommercial-License, permitting copying and reproduction so long as the original work is given appropriate credit. Contents may not be used for commercial purposes, or adapted, remixed, transformed or built upon. (https://creativecommons.org/ licenses/by-nc-nd/4.0/) Thieme Revinter Publicações Ltda., Rua do Matoso 170, Rio de Janeiro, RJ, CEP 20270-135, Brazil
} 


\section{Resumo}

\section{Palavras-chave \\ - neurocisticercose \\ - hidrocefalia \\ - neurônios \\ - modelo experimental}

inflammatory features in both groups. However, the density of oligodendrocytes and neurons within the periventricular region was lower in the high concentration group (5.18 versus 9.72 for oligodendrocytes and 15.69 versus 21.00 for neurons; $p<0.001$ for both).

Conclusion Our results suggest that, in rats, a higher concentration of $T$. crassiceps cyst proteins in the subarachnoid space could induce ventricle enlargement and reduce the number of neurons within the periventricular area.

Objetivo Modelos experimentais podem ajudar a entender a fisiopatologia da hidrocefalia associada à neurocisticercose. O presente estudo teve como objetivo comparar a extensão da hidrocefalia e dano tecidual em ratos com inoculação subaracnóidea de diferentes concentrações de proteínas de cistos de Taenia crassiceps.

Métodos Sessenta ratos jovens foram divididos em dois grupos: grupos de baixa e alta concentração. Os animais do grupo de baixa concentração receberam 0,02 ml de proteínas de cisto de $T$. crassiceps $(2,4 \mathrm{mg} / \mathrm{ml})$, enquanto os do grupo de alta concentração receberam $0,02 \mathrm{ml}$ de proteínas de cisto de $T$. crassiceps $(11,6 \mathrm{mg} / \mathrm{ml})$. Os animais foram submetidos à ressonância magnética 1,3 e 6 meses após a inoculação para avaliar o volume do ventrículo. A avaliação morfológica foi realizada no final do período de observação.

Resultados Medidas repetidas dos volumes ventriculares aos 1, 3 e 6 meses mostraram aumento progressivo dos ventrículos. Após 1 e 3 meses, não observamos diferenças nos volumes ventriculares entre os 2 grupos. No entanto, aos 6 meses, os ventrículos foram maiores no grupo de alta concentração (mediana $=3,86 \mathrm{~mm}^{3}$, variação: 2,37-12,68) em comparação com o grupo de baixa concentração (mediana $=2,00 \mathrm{~mm}^{3}$, variação: $0,37-11,57 ; p=0,003$ ). A avaliação morfológica revelou algumas características inflamatórias nos dois grupos. No entanto, a densidade de oligodendrócitos e neurônios na região periventricular foi menor no grupo de alta concentração (5,18 versus 9,72 para oligodendrócitos e 15,69 versus 21,00 para neurônios; $p<0,001$ para ambos).

Conclusão Nossos resultados sugerem que, em ratos, uma maior concentração de proteínas do cisto de $T$. crassiceps no espaço subaracnóideo poderia induzir o aumento do ventrículo e reduzir o número de neurônios na área periventricular.

\section{Introduction}

Neurocysticercosis (NC) is a common parasitic infection of the central nervous system (CNS) prevalent in Latin America, SubSaharan Africa, and Southeast Asia. Despite having a possibility of eradication, the disease remains endemic in communities with poor sanitary conditions and has reemerged in developed countries because of migratory flows. ${ }^{1-3}$

The course of the disease is dependent upon the number of parasites, their stage of development, distribution within the brain, the subarachnoid space and the ventricles, and parasite-host interaction. ${ }^{4}$ In the extraparenchymal form of the disease, the cysts of the tapeworm Taenia solium lodge in the cerebrospinal fluid (CSF) compartments and may cause meningitis, vasculitis, hydrocephalus, and raised intracranial pressure. $^{5,6}$ Hydrocephalus is one of the most devastating complications related to extraparenchymal NC. The high rate of infections and malfunctions of the ventricular shunts used to release hydrocephalus in patients with $\mathrm{NC}$ are the leading causes of the considerably high mortality in these patients. ${ }^{7}$ Neurocysticercosis-associated hydrocephalus may occur due to obstruction caused by the presence of cysts at the narrow point of the CSF flow pathway within the brain ventricles, or due to inflammation within the subarachnoid cisterns. ${ }^{8-10}$

The pathophysiology of NC-induced hydrocephalus and the therapeutic options for the treatment of this condition are well-studied. However, the heterogeneity of the disease among different populations and age groups, mainly concerning the clinical presentation and the response to medical treatment, is poorly understood. ${ }^{11}$ Experimental animal models of NC-induced hydrocephalus might help to address some of these issues.

Recently, we have developed a rat model of NC-induced hydrocephalus by cisternal inoculation of Taenia crassiceps cysts. In this model, we observed obstructive and inflammatory features that confirmed the successful induction of hydrocephalus. ${ }^{12}$ However, the role of inflammation in NCinduced hydrocephalus is not yet studied. Since in clinical 
practice, it is common to find patients with NC-related hydrocephalus without viable cysts, it might be possible that the degenerating cysts induce hydrocephalus. The present study aimed to assess whether cisternal inoculation of $T$. crassiceps cyst antigens in different concentrations could induce hydrocephalus and tissue damage of different severities.

\section{Methods}

\section{Experimental Animals}

Sixty male Wistar rats (Rattus norvegicus) aged 6 weeks were used in the present study. The animals were handled according to the current guidelines for the care and use of laboratory animals, and the local institutional review board approved the study project. The animals were kept under adequate sanitary conditions with food and water available ad libitum, in a room with a $12 \mathrm{~h}$ light/dark cycle under controlled temperature $\left(21^{\circ} \mathrm{C}\right)$.

The animals were randomly divided into 2 groups: low $(\mathrm{n}=30)$ and high concentration $(\mathrm{n}=30)$ T. crassiceps antigens inoculation groups. The animals underwent magnetic resonance imaging (MRI) at 1, 3, and 6 months after the inoculation. After the $3^{\text {rd }}$ MRI, the animals were euthanized and the brains were collected for histological assessment.

\section{T. crassiceps Antigens Preparation}

T. crassiceps cysts were maintained by subsequent inoculations in the peritoneal cavity of mice, where the cysts reproduce by gemmulation. ${ }^{13}$ The cysts were aseptically removed from the peritoneal cavity of mice and collected in beakers for immediate preparation of the antigenic suspensions. For the low concentration group, the cysts were resuspended in $100 \mathrm{ml}$ of saline and for the high concentration group no diluent solution was added. The cysts suspension was sonicated with $60 \%$ amplitude at $10^{\circ} \mathrm{C}$ until a homogenous suspension was obtained. The resulting suspensions were centrifuged at $0^{\circ} \mathrm{C}$ and $180 \mathrm{~Hz}$ for 5 minutes and the supernatant was collected. The concentration of the protein in the suspensions was determined by the Bradford method. The protein concentration in the low concentration group was $2.4 \mathrm{mg} / \mathrm{ml}$, and in the high concentration group, it was $11.6 \mathrm{mg} / \mathrm{ml}$.

\section{Inoculations}

The rats were anesthetized with an intraperitoneal injection of $0.1 \mathrm{ml} / \mathrm{kg}$ mixture of ketamine $(100 \mathrm{mg} / \mathrm{ml})$ and xylazine ( $20 \mathrm{mg} / \mathrm{ml})$. A $1-\mathrm{cm}$ long skin incision was made at the occipitocervical junction, followed by blunt dissection pf planes until reaching the skull, the posterior arc of the first vertebra, and the atlanto-occipital membrane. Next, $0.02 \mathrm{ml}$ of the cyst suspension was injected with a $25-G$ needle between the occipital bone and the first vertebrae, through the atlanto-occipital membrane towards the cisterna magna. The skin was sutured with a 4.0 mononylon suture.

\section{Magnetic resonance imaging}

Magnetic resonance imaging was performed using a Vet-MR 0.25 T equipment (Esaote, Santo André, SP, Brazil). For MRI examination, the animals were anesthetized with $0.5 \mathrm{ml} / \mathrm{kg}$ of the aforementioned mixture of xylazine and ketamine. The image acquisition protocol consisted of T2-weighted echo gradient acquisitions (slice thickness: $0.6 \mathrm{~mm}$, echo time: $5 \mathrm{~ms}$, repetition time: $10 \mathrm{~ms}$ ) which provided a good visualization of the dilated ventricles, as previously described. ${ }^{12}$ Ventricle volume was determined using ITK-SNAP version 3.0.0 software (GNU General Public License, Philadelphia, PA, USA) with a manual segmentation of the ventricles frame-byframe. The investigator was blinded to the animal groups.

\section{Morphological Assessment}

After the $3^{\text {rd }}$ MRI (6 months postinoculation), the animals were euthanized with an overdose of xylazine and ketamine. The animals were transcardially perfused with saline to wash out blood vessel contents, followed by $10 \%$ buffered formalin for tissue fixation. The brains were dissected out of the skull and cut in the coronal plane at the level of the optic chiasm. The samples were fixed in formalin overnight and then were dehydrated by transferring the tissue through solutions of increasing alcohol concentrations. Following this, the tissues were diafanized in xylene and embedded in paraffin. The blocks were sectioned into $5 \mu \mathrm{m}$ thick sections and the sections were stained with hematoxylin-eosin. The morphological assessment was carried out using a morphometric approach using stereological point-counting, by which a uniform grid is plotted over the image and the points crossing the lines are counted. ${ }^{14}$ The morphometric approach considered the mean number of neurons, oligodendrocytes, astrocytes, vessels, inflammatory cells, and lymphocytes in the periventricular and ependymal regions.

\section{Statistical Analysis}

The distribution of data was assessed with the Shapiro-Wilk test. Differences between the groups were assessed using the Student t-test or the Mann-Whitney test. Differences in repeated measures within the same groups were assessed using the paired t-test and the Wilcoxon test. The Fisher exact test was used to compare frequencies. Differences were considered significant for $p$-value $<0.05$. All statistical analyses were performed using IBM SPSS Statistics for Windows, version 21.0 (IBM Corp, Armonk, NY, USA).

\section{Results}

The periprocedural mortality was 9 and 19 in the low and high concentration groups, respectively. Among the remaining 21 rats in the low concentration group, 4 died during the follow-up and 1 after the $3^{\text {rd }}$ MRI. In the high concentration group, from the 11 remaining animals, 3 died during the follow-up period. Thus, imaging and histological assessment were performed on the remaining 16 rats in the low concentration group and 8 in the high concentration group.

Slight enlargement of the brain ventricles was observed in both groups postinoculation; the increase was more evident and significant in the high concentration group (-Fig 1), mainly at 6 months postinoculation. In the low concentration group, a significant increase was observed between 1 and 3 months postinoculation (medians $1.78 \mathrm{~mm}^{3}$ and $2.15 \mathrm{~mm}^{3}$, 


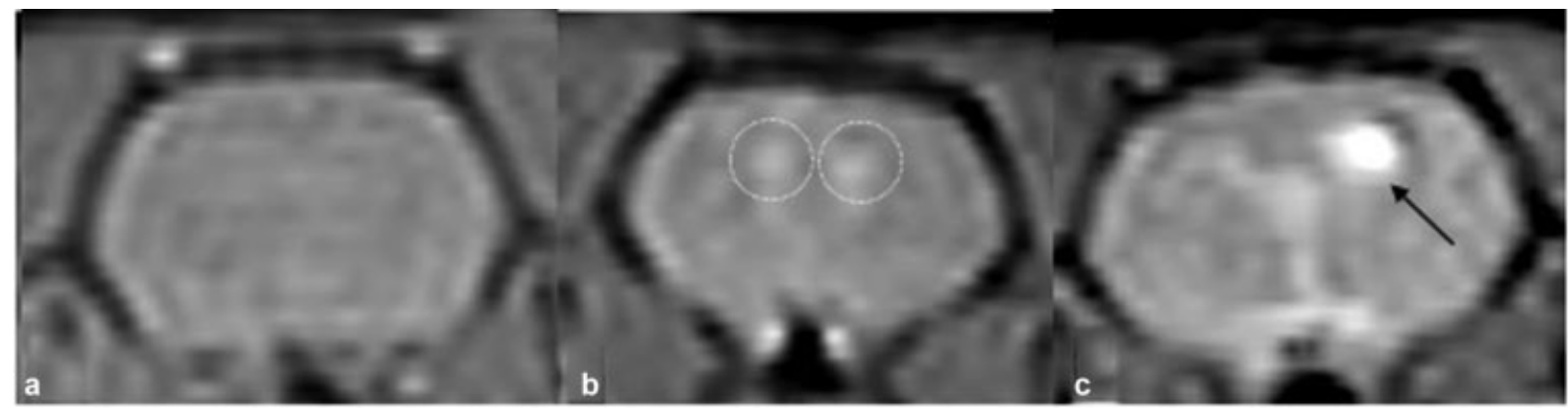

Fig. 1 Coronal magnetic resonance images (a) in the low-concentration group the ventricles cannot be visualized; (b) slight enlargement of the ventricles (dashed circles) in the high-concentration group; (c) an evident ventricle enlargement (arrow) from the high-concentration group.

Table 1 Ventricle volumes $\left(\mathrm{mm}^{3}\right)$ in the low- and high-concentration groups at 1, 3, and 6 months postinoculation

\begin{tabular}{|l|l|l|l|l|l|l|}
\hline Month & Group & Average & Standard deviation & Median & Range & $p$-value \\
\hline \multirow{3}{*}{3} & Low & 1.67 & 0.85 & $1.78^{\dagger}$ & $0.30-2.82$ & $0.180^{*}$ \\
\cline { 2 - 7 } & High & 2.64 & 2.25 & $2.04^{\ddagger}$ & $1.04-8.08$ & $0.397^{*}$ \\
\hline \multirow{2}{*}{6} & Low & 2.62 & 2.79 & $2.15^{\dagger}$ & $0.22-12.83$ & $0.45-11.20$ \\
\cline { 2 - 7 } & High & 3.16 & 3.58 & $1.89^{\ddagger}$ & $2.00^{\dagger}$ & $0.37-11.57$ \\
\end{tabular}

'Wilcoxon test for repeated measures. In the low-concentration group, ventricle volumes were different at 1 and 3 months $(p=0.032)$, but not at 3 and 6 months $(p=0.984)$.

${ }^{\ddagger}$ Wilcoxon test for repeated measures. In the high-concentration group, ventricle volumes were not different at 1 and 3 months ( $\left.p=0.646\right)$,but were different at 3 and 6 months $(p<0.05)$.

*Mann-Whitney test for independent samples. The ventricle volumes were not different between the two groups at 1 and 3 months, but were different at 6 months.

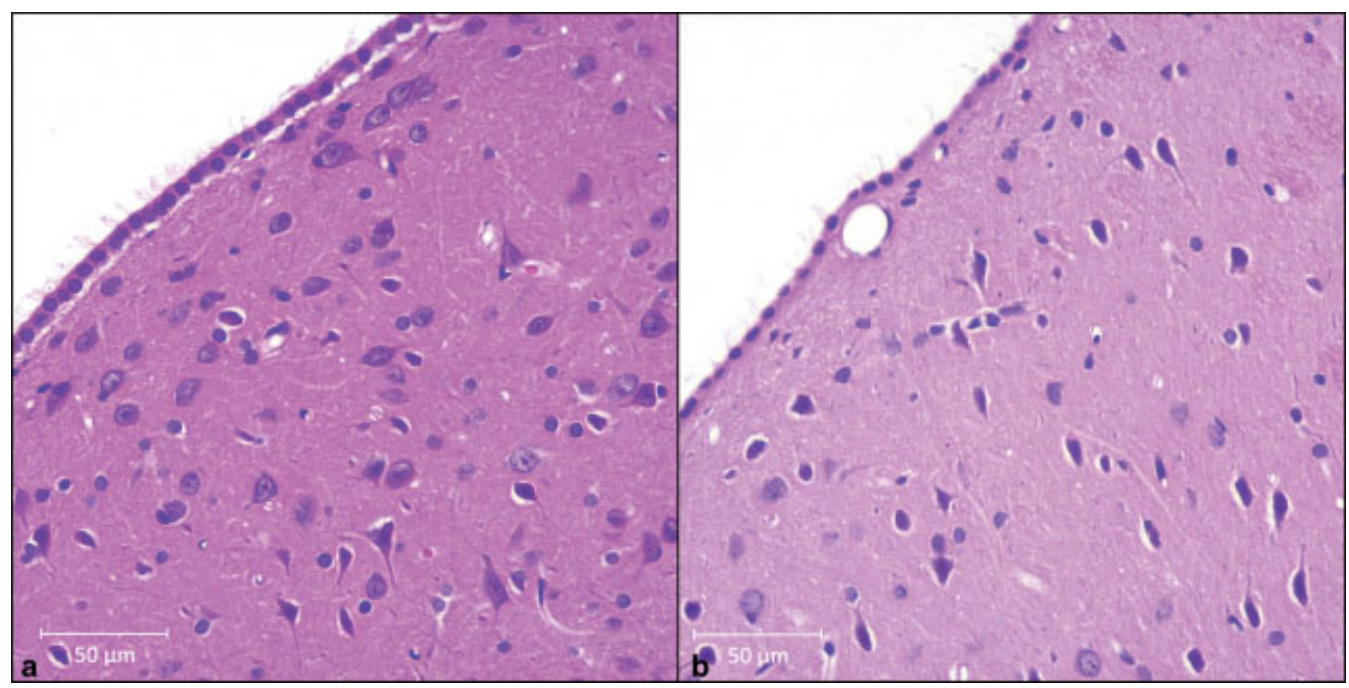

Fig. 2 Hematoxylin and Eosin staining of the brain sections depicting differences in neuronal density (a) the low-concentration group has a higher neuronal density compared to (b) the high-concentration group.

respectively), while in the high concentration group, a significant increase was observed between 3 and 6 months postinoculation (medians $1.89 \mathrm{~mm}^{3}$ and $3.86 \mathrm{~mm}^{3}$, respectively) (-Table 1). In the 1 and 3 months postinoculation follow-ups, the volumes of the ventricles were not different between the 2 groups ( $p=0.180$ and 0.397 , respectively). However, a significant difference in the ventricle volume was observed between the 2 groups at 6 months postinoculation (medians 2.00 versus $3.86 \mathrm{~mm}^{3} ; p=0.003$ ).

Morphological assessment revealed a few lymphocytes and new vessels in both groups. The ependymal lining was normal in both groups. The mean oligodendrocytes density was 9.72 and 5.18 in the low and high concentration groups, respectively $(p<0.001)$. Similarly, within the 
periventricular area, a significant difference in the neuronal density was observed between the 2 groups $(21.00$ versus 15.69, low versus high concentration group, $p<0.001$, - Figure 2). Conversely, there was no significant difference in astrocyte density between the two groups ( 2.89 versus 2.74 , low versus high concentration group, $p=0.73$ ).

\section{Discussion}

Neurocysticercosis is a preventable, but an embarrassingly neglected infectious disease still prevalent in nondeveloped countries. It remains endemic in several countries in Latin America, sub-Saharan Africa, and Southeast Asia. ${ }^{15}$ Experimental animal models of neurocysticercosis are a valuable tool to study the characteristics of inflammation and the basic mechanisms underlying the heterogeneous relationship between the parasite and the host. ${ }^{16}$

In a previous study, we observed that, in rats, cisternal inoculation of antigenic suspension of $T$. crassiceps cysts induced a slight increase in the ventricle volume, without any signs of inflammation. We speculated that it was due to the low concentration of the inoculated proteins and that the inoculation of a higher concentration of antigens could induce a more intense inflammatory response, and more evident hydrocephalus. ${ }^{17}$ Herein, we observed that the animals who received a higher concentration of $T$. crassiceps cyst proteins had a significantly higher ventricle volume than those who received a low concentration of cyst proteins at 6 months postinoculation, confirming the previous hypothesis. In our experimental model, the induction of hydrocephalus at 6 month postinoculation is dependent on the presence of living cysts. ${ }^{17}$ The live T. crassiceps cysts might continuously recruit the inflammatory cells and obstruct the narrow passages within the ventricles; thus, a combination of inflammation and mechanical obstruction may lead to hydrocephalus. ${ }^{17}$ In contrast, the antigenic suspension form of $T$. crassiceps cysts may evoke a transient inflammatory response that may cause slight enlargement of the lateral ventricles without obvious hydrocephalus. It might be possible that inoculating the animals with even a higher concentration of cyst proteins may lead to hydrocephalus; however, further studies are required to prove this other hypothesis.

Another possible explanation is that this slight ventricle enlargement is due to a brain atrophy caused by the inflammation evoked by the response against the parasite. Actually, the intraperitoneal inoculation of T. crassiceps is able to impair the learning performance of mice, which is accompanied by hippocampal sclerosis. Apoptosis of hippocampal cells may be related to a breakdown of the blood-brain barrier determined by the presence of circulating $T$. crassiceps metacestode factor. $^{18}$

Clinically, it has been well-documented that dead cysts may cause arachnoiditis, ependymitis, and hydrocephalus, ${ }^{19}$ which is one of the reasons for using corticosteroids to control inflammation during the antiparasitic treatment. ${ }^{20}$ A few studies have cautioned about the risk associated with intraoperative rupture of $T$. solium cysts, which may lead to ventriculitis $^{21,22}$; however, recent studies downplayed these risks. ${ }^{23-25}$ In the surgical management of hydatid cysts, the rupture of the cyst may worsen inflammation and lead to the seeding of infection. ${ }^{26,27}$

In the present study, inoculation of the animals with a higher concentration of $T$. crassiceps cyst antigens failed to induce remarkable ependymitis and hydrocephalus. A possible explanation is that inoculation does not mimic the natural degeneration of cysts observed in humans. Further studies on cyst degeneration using antiparasitic drugs are required to conclusively prove this. Another possibility is the obvious differences between the parasites (T. solium versus $T$. crassiceps) and the hosts (human versus rat).

We observed no significant difference in the number of inflammatory cells between the two groups. Moreover, the number of lymphocytes was low in both groups. Since the histopathological assessment was performed at 6 months after the inoculation, the possibility of a transitory and selflimited inflammation that followed the inoculation within the first few days cannot be ruled out.

Interestingly, we observed reduced oligodendrocytes and neuronal density in the periventricular area of animals from the high-concentration group, which may explain the neuropsychological changes observed in patients with neurocysticercosis. The association between dementia and neurocysticercosis was demonstrated a few years ago; patients with neurocysticercosis may present changes in working and episodic verbal memory, executive functions, naming, verbal fluency, constructive praxis, and visuospatial orientation. ${ }^{28-30}$ Recently, another group with interest in experimental models of neurocysticercosis showed increased demyelination and hippocampal disorganization following intraventricular inoculation of T. crassiceps cysts. ${ }^{31}$ However, these animals also presented ventricle enlargement, which might have caused the observed morphological changes. ${ }^{32,33}$ In the present study, despite the low volume of the ventricles, the animals with a higher concentration of cyst antigens presented a reduced neuronal density. Further studies are required to investigate the link between neuroinflammation and neurodegeneration, as well as between neurocysticercosis and mesial temporal sclerosis, which has been extensively demonstrated in clinical studies. $^{34-36}$ Besides, a recent clinical study has shown an interesting correlation between anti-brain protein autoantibodies and the levels of secreted T. solium glycoprotein HP-10, suggesting that the level of stimulation of the autoantibody response may be a function of the number of viable parasites. ${ }^{37}$ This information adds evidence to the link between neurocysticercosis and neuroinflammation.

Finally, the present study has limitations. First of all, we did not use a control group without interventions. However, in our experience with previous experiments, we found that the inoculation of saline leads to no change on MRI and histologic assessments. Second, we could not precise the extent of inflammation soon after the inoculations because histologic assessments were done only at the end of the experiments. It is possible that the animals with larger ventricles and more histologic impairments had a more exacerbate initial inflammatory response, but we cannot be certain of this point. 
In conclusion, we found that inoculation of a higher concentration of $T$. crassiceps antigens in the subarachnoid space of rats leads to a more remarkable ventricle enlargement and a significant reduction in the neuronal density within the periventricular area.

\section{Conflict of Interests}

The authors have no conflict of interests to declare.

\section{Acknowledgment}

We thank Dr Agnès Fleury (UNAM) for her comments on this manuscript.

\section{References}

1 World Health Organization Taeniasis/cysticercosis [Online] Available at: http://www.who.int/taeniasis/en/ [Accessed on February 11th, 2020].

2 Coyle CM, Mahanty S, Zunt JR, et al. Neurocysticercosis: neglected but not forgotten. PLoS Negl Trop Dis 2012;6(05):e1500

3 Fabiani S, Bruschi F. Neurocysticercosis in Europe: Still a public health concern not only for imported cases. Acta Trop 2013;128 (01):18-26

4 Gripper LB, Welburn SC. Neurocysticercosis infection and disease-A review. Acta Trop 2017;166:218-224

5 Bazan R, Hamamoto Filho PT, Luvizutto GJ, et al. Clinical Symptoms, Imaging Features and Cyst Distribution in the Cerebrospinal Fluid Compartments in Patients with Extraparenchymal Neurocysticercosis. PLoS Negl Trop Dis 2016;10(11):e0005115

6 Marcin Sierra M, Arroyo M, Cadena Torres M, et al. Extraparenchymal neurocysticercosis: Demographic, clinicoradiological, and inflammatory features. PLoS Negl Trop Dis 2017;11(06):e0005646

7 Kelley R, Duong DH, Locke GE. Characteristics of ventricular shunt malfunctions among patients with neurocysticercosis. Neurosurgery 2002;50(04):757-761, discussion 761-762

8 Matushita H, Pinto FCG, Cardeal DD, Teixeira MJ. Hydrocephalus in neurocysticercosis. Childs Nerv Syst 2011;27(10):1709-1721

9 Hamamoto Filho PT, Zanini MA, Fleury A. Hydrocephalus in Neurocysticercosis: Challenges for Clinical Practice and Basic Research Perspectives. World Neurosurg 2019;126:264-271

10 de Oliveira RS, Viana DC, Colli BO, Rajshekhar V, Salomão JFM. Pediatric neurocysticercosis. Childs Nerv Syst 2018;34(10): 1957-1965

11 Fleury A, Escobar A, Fragoso G, Sciutto E, Larralde C. Clinical heterogeneity of human neurocysticercosis results from complex interactions among parasite, host and environmental factors. Trans R Soc Trop Med Hyg 2010;104(04):243-250

12 Hamamoto Filho PT, Fabro AT, Rodrigues MV, et al. Taenia crassiceps injection into the subarachnoid space of rats simulates radiological and morphological features of racemose neurocysticercosis. Childs Nerv Syst 2017;33(01):119-123

13 Willms K, Zurabian R. Taenia crassiceps: in vivo and in vitro models. Parasitology 2010;137(03):335-346

14 Weibel ER, Kistler GS, Scherle WF. Practical stereological methods for morphometric cytology. J Cell Biol 1966;30(01):23-38

15 Fleury A, Sciutto E, de Aluja A, Carpio A. Cysticercosis: A Preventable, but Embarrassing Neglected Disease Still Prevalent in NonDeveloped Countries. In: Sing A(eds). Zoonoses - Infections Affecting Humans and Animals. SpringerDordrecht2015

16 Nash TE, Singh G, White AC, et al. Treatment of neurocysticercosis: current status and future research needs. Neurology 2006;67 (07):1120-1127

17 Hamamoto Filho PT, Fogaroli MO, Oliveira MAC, et al. A Rat Model of Neurocysticercosis-Induced Hydrocephalus: Chronic Progres- sive Hydrocephalus with Mild Clinical Impairment. World Neurosurg 2019;132:e535-e544

18 Zepeda N, Copitin N, Chávez JL, et al. Hippocampal sclerosis induced in mice by a Taenia crassiceps metacestode factor. J Helminthol 2019;93(06):690-696

19 Fleury A, Carrillo-Mezo R, Flisser A, Sciutto E, Corona T. Subarachnoid basal neurocysticercosis: a focus on the most severe form of the disease. Expert Rev Anti Infect Ther 2011;9(01): 123-133

20 White AC Jr, Coyle CM, Rajshekhar V, et al. Diagnosis and Treatment of Neurocysticercosis: 2017 Clinical Practice Guidelines by the Infectious Diseases Society of America (IDSA) and the American Society of Tropical Medicine and Hygiene (ASTMH). Clin Infect Dis 2018;66(08):1159-1163

21 Madrazo I, García-Rentería JA, Sandoval M, López Vega FJ. Intraventricular cysticercosis. Neurosurgery 1983;12(02): 148-152

22 Jiménez-Vázquez OH, Nagore N. Endoscopic evidence of ventricular and cisternal inflammatory changes after intraoperative cysticercal rupture during endoscopic third-ventriculostomy removal. Br J Neurosurg 2013;27(01):137-138

23 Psarros TG, Krumerman J, Coimbra C. Endoscopic management of supratentorial ventricular neurocysticercosis: case series and review of the literature. Minim Invasive Neurosurg 2003;46 (06):331-334

24 Bergsneider M, Holly LT, Lee JH, King WA, Frazee JG. Endoscopic management of cysticercal cysts within the lateral and third ventricles. J Neurosurg 2000;92(01):14-23

25 Kaif M, Husain M, Ojha BK. Endoscopic Management of Intraventricular Neurocysticercosis. Turk Neurosurg 2019;29(01):59-65

26 Ozek MM. Complications of central nervous system hydatid disease. Pediatr Neurosurg 1994;20(01):84-91

27 Tuzun Y, Solmaz I, Sengul G, Izci Y. The complications of cerebral hydatid cyst surgery in children. Childs Nerv Syst 2010;26(01): 47-51

28 Ramirez-Bermudez J, Higuera J, Sosa AL, Lopez-Meza E, LopezGomez M, Corona T. Is dementia reversible in patients with neurocysticercosis? J Neurol Neurosurg Psychiatry 2005;76(08): 1164-1166

29 Ciampi de Andrade D, Rodrigues CL, Abraham R, et al. Cognitive impairment and dementia in neurocysticercosis: a cross-sectional controlled study. Neurology 2010;74(16):1288-1295

30 Rodrigues CL, de Andrade DC, Livramento JA, et al. Spectrum of cognitive impairment in neurocysticercosis: differences according to disease phase. Neurology 2012;78(12):861-866

31 Moura VBL, Milhomem AC, Lima SB, et al. Demyelination in experimental intraventricular neurocysticercosis. Arq Neuropsiquiatr 2020;78(02):103-111

32 McAllister JP II. Neuronal damage in hydrocephalus. J Neurosurg 2006;104(05):297-298, discussion 298

33 Hamamoto Filho PT, Moreira CAA, Generoso D, Alves Júnior AC, Zanini MA. Experimental neurocysticercosis and demyelination. Arq Neuropsiquiatr 2020. Ahead of print

34 Gripper LB, Welburn SC. The causal relationship between neurocysticercosis infection and the development of epilepsy - a systematic review. Infect Dis Poverty 2017;6(01):31

35 Carpio A, Fleury A, Romo ML, Abraham R. Neurocysticercosis: the good, the bad, and the missing. Expert Rev Neurother 2018;18 (04):289-301

36 Singh G, Sander JW. Neurocysticercosis as a probable risk factor for hippocampal sclerosis. Arq Neuropsiquiatr 2018;76(11): 783-790

37 Parkhouse RME, Carpio A, Cortez MM, von Kriegsheim A, Fesel C. Anti-brain protein autoantibodies are detectable in extraparenchymal but not parenchymal neurocysticercosis. J Neuroimmunol 2020;344:577234 